\title{
PENILAIAN POTENSI OBJEK DAN DAYA TARIK WISATA TELUK MIOKA DAN ALTERNATIF PENGELOLAANNYA DI KABUPATEN KEPULAUAN YAPEN
}

\section{(Assessment of Potential Tourist Attractions at Mioka Bay and Its Alternative Managements in District of Kepulauan Yapen)}

\author{
Hermelina Novalin Taribaba ${ }^{1}$ Matheus Beljai ${ }^{\bowtie}$ dan Mariana H. Peday ${ }^{1}$ \\ Jurusan Kehutanan, Fakultas Kehutanan Universitas Papua Manokwari, Papua Barat, \\ 98314. Tlp/Fax: +62986211065 . \\ ${ }^{\bowtie}$ Penulis Korespondensi: Email: beljaimatheus@gmail.com \\ Diterima: 16 Oct 2017| Disetujui: 20 Nov 2017
}

\begin{abstract}
Abstrak
Penelitian ini bertujuan untuk mengetahui potensi objek dan daya tarik wisata alam guna menyusun alternatif pengelolaan potensi objek dan daya tarik wisata alam Teluk Mioka dengan menggunakan metode deskriptif dengan teknik observasi lapang dan wawancara semi struktural. Hasil penelitian menunjukan bahwa lokasi wisata Teluk Mioka memiliki potensi untuk dikembangkan dan berpeluang untuk dijadikan sebagai salah satu daerah tujuan wisata alam karena memberi penawaran yang baik. Ada alternatif pengelolaan yang dipandang penting untuk dikembangkan sebagai wisata alam Teluk Mioka yaitu alternatif pengelolaan terhadap daya tarik, alternatif pengelolaan terhadap aksesbilitas dan sarana prasarana penunjang serta alternatif pengelolaan terhadap kondisi lingkungan lokasi wisata. Hasil perhitungan dari setiap kriteria seperti nilai kriteri dari daya tarik objek wisata dengan nilai 990, aksesbilitas nilai 625, sarana dan prasarana penunjang nilai 120 dan kondisi lingkungan lokasi wisata dengan 875. Nilai total kriteria Teluk Mioka adalah 2610 dan dikategorikan baik.
\end{abstract}

Kata kunci: obyek wisata, interaksi, keindahan alam, hutan pesisir, keanekaragaman hayati

\begin{abstract}
This study aimed at knowing potential tourism and attractive natural spots for designing a further alternative management plan of the objects at Mioka bay through descriptive method including direct field observation as well as semi-structured interviews. The results pointed out that the bay had a potential indication to be developed and managed in a proper way for generating multiple benefits. In detail, more efforts were needed to be address such as managing attraction spots, accessibility, infrastructure, and the overall environmental aspects surrounding the location. Based on criteria, it can be denoted that the highest score was given to the aspect of tourism attraction spots (990), while accessibility was 625, infrastructure was 120, and the overall surrounding environmental was 875. All in all, the given scoring criteria for Mioka bay was 2610 and was indicated good.
\end{abstract}

Keywords: tourist object, interaction, nature beauty, coastal forest, biodiversity 


\section{PENDAHULUAN}

Kepariwisataan dalam UU RI No.10 Tahun 2009 dimaksud sebagai keseluruhan kegiatan yang terkait dengan pariwisata dan bersifat multidimensi serta multidisiplin yang muncul sebagai wujud kebutuhan setiap orang dan negara serta interaksi antara wisatawan dan masyarakat setempat, sesama wisatawan, pemerintah, pemerintah daerah, dan pengusaha. Secara umum tujuan dari pembangunan kepariwisataan di Indonesia adalah untuk meningkatkan perekonomian secara nasional maupun daerah. Oleh karena itu, kepariwisataan secara langsung maupun tidak langsung diarahkan untuk meningkatkan kegiatan ekonomi masyarakat dan sekaligus berperan dalam upaya peningkatan kesejahteraan dan pendapatan masyarakat.

Dalam keparawisataan segala sesuatu yang memiliki keunikan, keindahan, dan nilai yang berupa keanekaragaman kekayaan alam, budaya dan hasil buatan manusia yang menjadi sasaran atau tujuan kunjungan wisatawan merupakan daya tarik wisata (Kementerain Pariwisata 2009). Menurut Soemarno (2010), kekayaan sumber daya alam yang dapat dimanfaatkan sebagai objek wisata alam seperti gunung, taman laut, sungai, pantai, flora termasuk hutan, fauna, air terjun, danau dan pemandangan alam.

Papua termasuk salah satu provinsi di Indonesia dengan kekayaan keanekaragaman hayati, keindahan, bentang alam, peninggalan sejarah serta keaslian dan keunikan budaya-budaya tradisional, yang menarik dan potensial sebagai objek dan daya tarik wisata (Wanma et al. 2013). Potensi objek dan daya tarik wisata tersebut tersebar pada wilayah-wilayah yang strategis di Papua, salah satunya di Kabupaten Kepulauan Yapen.

Kabupaten Kepulauan Yapen termasuk salah satu kabupaten di Provinsi Papua yang memiliki luas $2.023 \mathrm{~km}^{2}$. Secara geografis daerah ini memiliki wilayah yang terdiri dari gugusan pulau dan terdapat potensi objek dan daya tarik wisata yang menarik, antara lain Teluk Mioka.

Teluk Mioka adalah salah satu teluk yang memiliki perpaduan warna air hijau kebiru-biruan serta ketenangan air memberikan nuansa keindahan tersendiri. Teluk ini berbatasan langsung dengan laut dan berada di Kampung Sarwandori, Distrik Kosiwo. Saat ini upaya pengembangan wisata pemerintah daerah mulai dilakukan, antara lain dengan membangun tempat-tempat wisata untuk meningkatkan ekonomi masyarakat sekitar. Sebab itu perlu ketersedian data dan informasi secara ilmiah untuk pengembangan atau pengelolaan Teluk Mioka sebagai salah satu daerah tujuan wisata. Penelitian ini bertujuan untuk mengetahui potensi objek dan daya tarik wisata alam serta menyusun alternatif pengelolaan potensi objek dan daya tarik wisata alam Teluk Mioka. Dengan tersediannya informasi ini, dapat membantu pemerintah daerah dalam strategi pengembangan Teluk Mioka menjadi daerah tujuan wisata yang dapat memberikan sumbangan penerimaan ahli daerah (PAD) serta meningkatkan ekonomi masyarakat.

\section{METODE PENELITIAN}

Penelitian ini dilaksanakan di Teluk Mioka Kampung Sarwandori Distrik Kosiwo Kabupaten Kepulauan Yapen 
dengan durasi waktu penelitian \pm 2 minggu dari tanggal 14 hingga 28 Juli tahun 2016. Penelitian ini berbasis pada metode deskriptif dengan teknik observasi lapang (penjelajahan pada lokasi penelitian) dan wawancara semi structural pada masyarakat pemilik Kawasan dan stakeholder terkait. Variabel yang diamati dalam penelitian ini adalah potensi objek dan daya tarik wisata di sekitar Teluk Mioka.

\section{Pelaksanaan Penelitian}

\section{Penentuan Responden}

Responden contoh dibagi menjadi dua yaitu respoden kunci dan respoden umum. Responden kunci terdiri dari instasi pemerintah terkait (dinas parawisata dan perikanan) kepala kampung, kepala distrik dan pemilik hak wilayat Teluk Mioka. Sedangkan responden umum terdiri dari masyarakat setempat ditentukan secara acak sederhana sebanyak $25 \%$ dari $84 \mathrm{KK}$, sehingga semua diperoleh 21 responden terdiri dari 2 (dua) kampung yaitu Kampung Sarwandori 1 dan Kampung Sarwandori 2

\section{Teknik Pengumpulan Data}

Data yang dikumpulkan terdiri dari: data primer dan data sekunder. Data primer dikumpulkan dengan teknik observasi lapang, jelajah dan wawancara semi struktural. Data yang dikumpulkan meliputi: data yang diambil secara langsung di lapangan seperti objek dan dan daya tarik wisata, aksesbilitas, sarana dan prasarana penujang dan kondisi lingkungan lokasi wisata. Sedangkan yang akan diwawancarai adalah masyarakat setempat dan pejabat dari instansi terkait. Data sekunder diperoleh dengan studi pustaka dari laporan dan hasil-hasil penelitian sejenis yang berasal dari intansi terkait. Data yang dikumpulkan meliputi : keadaan fisik kawasan atau kondisi sekitar lokasi penelitian seperti letak dan luas, topografi dan kelerengan, kondisi tanah, iklim, sarana transportasi, dan kondisi sosial masyarakat.

\section{Analisis Data}

Data yang dikumpulkan selanjutnya diolah dan dianalisi secara tabulasi dengan meteode skoring. Meteode skoring menggunakan modifikasi Pedoman Analisis Daerah Operasi dan Daya Tarik Wisata Alam tahun 2003 dari Direktur Jenderal perlindungan Hutan dan Konservasi Alam (PHKA). Pedoman ini memiliki beberapa kriteria yang digunakan adalah daya tarik, aksesibilitas, sarana dan prasarana penunjang serta kondisi lingkungan lokasi wisata. Pengambilan data dilakukan melalui mengisi kriteria yang sesuai dengan kondisi dan gambaran kawasan.

Penilaian kriteria daya tarik kawasan objek meliputi unsur-unsur seperti keindahan, keselamatan disekitar teluk, jenis pasir, variasi kegiatan, kebersihan air dan lebar pantai serta kebersihan atau kenyamanan kawasan. Bobot kriteria daya tarik diberi angka tertinggi yaitu 6 , hal ini mengingat daya tarik merupakan modal utama yang memungkinkan datangnya pengunjung.

Penilaian aksesbilitas meliputi unsurunsur kondisi dan jarak jalan darat, frekuensi kendaraan umum dari pusat kota ke objek wisata (berapa kali/hari dan jumlah kendaraan umum di kabupaten objek berada. Bobot nilai Aksesbilitas adalah 5, karena merupakan faktor yang sangat penting dalam mendorong potensi pasar 
Unsur-unsur yang terkandung dalam penilaian kriteria sarana dan prasarana penunjang meliputi sarana dan prasarana penunjang. Bobot nilai kriteria sarana dan prasarana penunjang adalah 3 .

Unsur-unsur penilaian kondisi lingkungan lokasi wisata meliputi tata ruang wilayah objek, status pemilikan lahan, kepadatan penduduk, sikap masyarakat terhadap objek, tingkat pengangguran, mata pencaharian penduduk, pendidikan dan media yang masuk. Bobot nilai kriteria kondisi lingkungan sosial ekonomi adalah 5 . Dalam Menentukan penilaian ada Beberapa langkah dalam menentukan penilaian. langkah pertama adalah penentuan nilai skor dengan persamaan (Departemen Kehutanan 2007), Dengan persamaan :

$$
\mathbf{S}=\mathbf{B} \times \mathbf{N}
$$

Keterangan :

$\mathrm{S}=$ Nilai kriteria

$\mathrm{B}=$ Bobot nilai kriteria

$\mathrm{N}=$ Jumlah nilai unsur-unsur kriteria

Langkah kedua adalah penentuan kategori penilaian. Kategori disusun berdasarkan jumlah total dari setiap dan seluruh penilaian. Dalam penelitian yang telah dilakukan oleh Oktadiyani (2006), kategori penilaian akan dihitung dengan menggunakan persamaan:

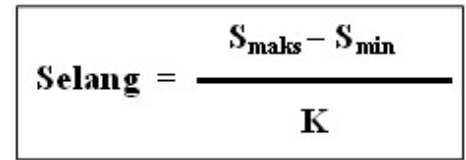

Dengan

Selang $=$ Nilai selang dalam penetapan selang kategori penilaian;

$\mathrm{S}_{\text {maks }}=$ Nilai skor tertinggi;

$\mathrm{S}_{\min }=$ Nilai skor terendah;

$\mathrm{K}$ = Banyaknya kategori penilaian

Penelitian ini menggunakan 5 tingkat kategori, yaitu sangat baik, baik, sedang, buruk, dan sangat buruk (tabel 1). Langkah ketiga adalah memasukkan total skor dari penilaian (dari langkah pertama) ke dalam kategori penilaian. Penentuan kategori dilakukan berdasarkan selang yang telah dilakukan. Berdasarkan kategori, dapat diketahui gambaran dari kondisi Teluk Mioka. Pada tabel.1, kategori dan selang penilaian potensi wisata Teluk Mioka (keterangan table 1). Selanjutnya hasil pengolahan dan analisis data diuraikan secara deskriptif dan hasilnya disajikan dalam bentuk tabel dan gambar (foto).

Tabel 1. Kategori dan selang penilaian potensi wisata Teluk Mioka

\begin{tabular}{lcc}
\hline No. & Kategori & Interval/Selang \\
\hline 1. & Sangat buruk & $1080-1531$ \\
2. & Buruk & $1532-1983$ \\
3. & Sedang & $1984-2435$ \\
4. & Baik & $2436-2887$ \\
5. & Sangat baik & $2888-3340$ \\
\hline
\end{tabular}

Sumber: Oktadiyani, 2006 


\section{HASIL DAN PEMBAHASAN}

\section{Letak dan Luas Teluk Mioka}

Teluk Mioka terletak pada Kampung Sarwandori Distrik Kosiwo Kabupaten Kepulauan Yapen. Secara geografis terletak antara koordinat $1^{0} 51^{\prime} 15^{\prime \prime}$ sampai 1 1052' 28' Lintang Selatan dan $136^{\circ} 11 ' 27$ ' sampai $136^{\circ} 12$ ' $10^{\prime \prime}$ Bujur Timur. Sebelah utara berbatasan dengan Distrik Windesi, sebelah timur berbatasan Kampung Mariadei, sebelah selatan berbatasan Laut Saireri dan sebelah barat berbatasan Kampung Aromarea. Luas Teluk Mioka adalah \pm 263.35 ha, kata Mioka terdiri lima nama tempat yang berada pada Kampung Sarwandori yaitu Manderi, Inumi, Onowai, Kayapasinai dan Aitaturi. Teluk Mioka juga masyarakat menyebutkan sebagai teluk yang teduh dan tenang.

\section{Daya Tarik Objek Wisata}

Daya tarik wisata merupakan salah satu unsur penting dalam dunia kepariwisataan. Menurut Inskeep (1991), daya tarik merupakan faktor utama yang menarik wisatawan mengadakan perjalanan mengunjungi suatu tempat. Adanya daya tarik yang ditawarkan suatu lokasi merupakan alasan utama pengunjung untuk datang ke lokasi tersebut untuk melakukan kegiatan wisata.

Teluk Mioka memiliki begitu banyak daya tarik yang cukup kuat untuk bisa menarik minat wisatawan. Daya tarik tersebut dapat berupa sumber daya alam yang menonjol misalnya flora atau pun fauna, keindahan panorama, variasi kegiatan atau atraksi kegiatan wisata yang dapat dilakukan di lokasi wisata misalnya kegiatan menikmati pandangan, kuliner, berenang, naik perahu, dan lain-lain. Daya tarik juga berupa kebersihan, keamanan dan juga kenyamanan lokasi wisata. Setiap daya tarik tersebut memiliki nilai masing-masing dan nilai tersebut menunjukkan seberapa kuat suatu daya tarik bisa menarik minat pengunjung. Penilaian terhadap kriteria daya tarik dapat dilihat pada tabel. 2 .

Tabel 2. Hasil penilaian kriteria daya tarik wisata Teluk Mioka

\begin{tabular}{llccc}
\hline \multicolumn{4}{c}{ Kriteria Daya Tarik } \\
\hline No. & Unsur & Bobot & Nilai unsur & *Nilai kriteria \\
\hline 1. & Keindahan & 6 & 30 & 180 \\
2. & Keselamatan di sekitar teluk & 6 & 25 & 150 \\
3. & Jenis pasir & 6 & 25 & 150 \\
4. & Variasi Kegiatan & 6 & 25 & 150 \\
5. & Kebersihan air & 6 & 20 & 120 \\
6. & Lebar pantai (diukur waktu surut) & 6 & 20 & 120 \\
7. & Kebersihan atau kenyamanan & 6 & 20 & 120 \\
\multicolumn{2}{c}{ Total Nilai Kriteria } & & 165 & 990 \\
\hline
\end{tabular}

Sumber: Data primer, 2016

Keterangan: *Hasil kali antara bobot dengan nilai unsur

Dari hasil penilaian terhadap kriteria daya tarik wisata Teluk Mioka pada tabel
2, diperoleh total dari nilai kriteria daya tarik yaitu 990 dengan unsur yang dinilai 
yaitu keindahan 180, keselamatan di sekitar teluk 150 , jenis pasir 150 , variasi kegiatan 150, kebersihan air 120, lebar pantai (diukur waktu surut) 120 dan kebersihan atau kenyamanan dengan nilai 120.

\section{Keindahan Teluk Mioka}

Keindahan Teluk Mioka memiliki variasi pandangan teluk, pulau/gunung di laut, kerindangan tepi pantai, keragaman daya tarik flora dan fauna dan ada ciri khusus (keunikan) sehingga diberi skor 30.

\section{Keselamatan di Sekitar Teluk Mioka}

Keselamatan di Teluk Mioka diberi skor 25 karena unsur keselamatan yang dinilai yaitu tidak ada arus balik berbahaya dan tidak ada kecuraman dasar, bebas dari gangguan binatang atau hewan berbahaya dan tidak ada kepercayaan yang mengganggu.

\section{Kebersihan Air}

Keberadaan Teluk Mioka berada pada Kampung Sarwandori sehingga kebersihan air berpeluang mendapat pengaruh dari pemukiman warga setempat dan sumber pencemaran lainnya seperti tempat pembuangan sampah domestik yang dekat dengan Teluk Mioka. Pada saat penelitian kebersihan air pada Teluk Mioka masih terjaga karena tidak ada aktifitas yang lebih berpengaruh terhadap kebersihan air sepeti pengaruh sungai, pengaruh pelelangan ikan/pasar/pabrik dan pengaruh dari pelabuhan. Kebersihan air diberi skor 20.

\section{Kebersihan Lokasi}

Kebersihan dinilai berdasarkan keberadaan sampah pada lingkungan objek. Saat penelitian dilaksanakan di lokasi objek wisata Teluk Mioka keberadaan sampah masih terlihat dan pembersihan tidak dilakukan. Selain itu juga, tidak ada tempat penumpukan sampah yang disediakan di lingkungan objek wisata sehingga penguujung yang datang ke lokasi objek membuang sampah dengan sembarangan sehingga diberi skor 20.

\section{Jenis Pasir dan Lebar Pantai Teluk Mioka}

Salah satu daya tarik yang dimiliki oleh suatu objek wisata antaranya adalah jenis pasir dan lebar pantai. jenis pasir yang dimiliki oleh pantai Teluk Mioka adalah pasir putih dan sedikit patahan karang sehingga diberi skor 25 sedangkan lebar pantai dari pantai Teluk Mioka yaitu $50-100 \mathrm{~m}$ sehingga diberi skor 20 .

\section{Variasi Kegiatan}

Variasi kegiatan atau atraksi kegiatan wisata yang dapat dilakukan di lokasi wisata juga merupakan faktor utama yang menarik wisatawan pengunjung untuk datang ke lokasi tersebut. Teluk Mioka juga memiliki variasi kegiatan seperti kegiatan menikmati pandangan, kuliner, berenang, naik perahu (banana boot dan perahu tradisional), mancing, fotografi dan snorclin. Setiap unsur tersebut memiliki nilai seberapa kuat unsur-unsur tersebut dapat menarik minat wisatawan untuk berkunjung, sehingga diberi skor 25.

\section{Flora dan Fauna}

Keadaan flora di sekitar Teluk Mioka merupakan vegetasi-vegetasi umum yang terdapat di hutan pantai seperti Barringtonia asiatica, Calophypillum inophyllum, Terminalia catappa, Pandanus tectorius, Cocos nucifera dan lain-lain, tersaji pada tabel 3. 
Tabel 3. Jenis-jenis vegetasi di sekitar Teluk Mioka

\begin{tabular}{|c|c|c|c|}
\hline \multirow{2}{*}{ No. } & \multicolumn{2}{|c|}{ Spesies } & \multirow{2}{*}{ Famili } \\
\hline & Nama Latin & Nama perdagangan & \\
\hline 1. & Barringtonia asiatica & Butun & Licytidaceae \\
\hline 2. & Terminalia catappa & Ketapang & Combretaceae \\
\hline 3. & Pandanus tectorius & Pandan duri & Pandanaceae \\
\hline 4. & Cocos nucifera & Kelapa & Arecaceae \\
\hline 5. & Casuarina equisetifolia linn & Cemara laut & Casuarinaceae \\
\hline 6. & Spathoglottis plicata & Anggrek tanah & Orchidaceae \\
\hline 7. & Insia palembanica & Merbau & Fabaceae \\
\hline 8. & Alstonia schsolari $r . b r$ & Pulai & Apocynaceae \\
\hline 9. & Calophypillum inophyllum & Bintangur & Clusiaceae \\
\hline 10. & Pometia pinnata & Matoa & Sapindaceae \\
\hline 11. & Piper aduncum & Sirih hutan & Piperaceae \\
\hline 12. & Sterculla parkinsoni & Kayu seman & Sterculliaceae \\
\hline 13. & Ficus septica & Buah roda & Moraceae \\
\hline 14. & Myrstica $s p$ & Pala & Myrstaceae \\
\hline 15. & Morinda citrifolia & Mengkudu & Rubiceae \\
\hline 16. & Homalium foetidum & Gia/Malas & Flacourtiaceae \\
\hline
\end{tabular}

Sumber: Data primer, 2016

Teluk Mioka juga memiliki keanekaragaman sumber daya laut seperti jenis ikan, lamon, biota laut dan makro alga atau rumput laut. Masyarakat kampung Sarwandori juga membudidayakan rumput laut di dalam Teluk Mioka. Hasil pengamatan menunjukkan bahwa rumput laut bernilai ekonomis yang dibudidayakan adalah Eucheuma cottoni. Jenis bibit rumput laut tersebut didapatkan dari Dinas Perikanan dan Kelautan untuk budidayakan di Kampung Sarwandori, karena faktor lingkungan dan parameter air mendukung untuk membudidayakan makro alga tersebut. Rumput laut yang dibudidayakan diolah sebagai bahan makanan seperti agar-agar, stick dan mie. Sehingga makanan dari rumput laut bisa menjadi kuliner yang dapat dinikmati oleh wisatawan di Teluk Mioka.

\section{Aksesibilitas}

Perjalanan dari Serui ke Kampung Sarwandori dapat ditempuh dalam waktu sekitar 15 menit dengan menggunakan angkutan umum, angkutan umun yang menuju ke Kampung Sarwandori dengan ongkos perjalanan sebesar Rp. 10.000. Saat penelitian jalan baru diperbaiki, tipe jalan menuju Kampung Sarwandori adalah jalan aspal dengan lebar jalan lebih dari tiga meter. Kondisi jalannya yang baik dengan jarak sekitar $12 \mathrm{~km}$ dari kota Serui membuat akses ke Teluk Mioka tidak begitu sulit. Penilaian untuk kriteria aksesibilitas Teluk Mioka dapat dilihat pada tabel 4 . 
Tabel 4. Hasil penilaian kriteria aksesibilitas Teluk Mioka

\begin{tabular}{|c|c|c|c|c|}
\hline \multicolumn{5}{|c|}{ Kriteria aksesibilitas } \\
\hline No. & unsur & bobot & Nilai unsur & *Nilai kriteria \\
\hline 1. & Kondisi jarak Jalan Darat & 5 & 80 & 400 \\
\hline 2. & $\begin{array}{l}\text { Frekuensi kendaraan umum dari pusat kota } \\
\text { ke obyek wisata (berapa kali/hari) }\end{array}$ & 5 & 20 & 100 \\
\hline 3. & Jalan menuju tempat wisata & 5 & 25 & 125 \\
\hline & Total nilai kriteria & & 125 & 625 \\
\hline
\end{tabular}

Sumber: Data primer, 2016

Keterangan: *Hasil kali antara bobot dengan nilai unsur

Berdasarkan tabel 4, total dari nilai kriteria daya tarik yaitu 625 dengan unsur yang dinilai yaitu kondisi jarak jalan darat nilai 400, Frekuensi kendaraan umum dari pusat kota ke objek wisata (berapa kali/hari) nilai 100 dan jalan menuju tempat wisata 125 .

Mackinnon et al. (1990), menyatakan bahwa dua diantara beberapa faktor yang membuat suatu tempat wisata menarik bagi pengunjung adalah letaknya yang dekat, cukup dekat atau jauh dengan bandar udara internasional atau pusat wisata utama atau pusat kota dan juga perjalanan ke tempat wisata tersebut apakah mudah dan nyaman, perlu sedikit usaha, sulit atau berbahaya. Aksesibilitas Serui menuju ke Kampung Sarwandori sudah bisa dikatakan sangat baik karena memiliki kondisi jalan yang baik, dengan tipe jalan aspal dengan lebar lebih dari tiga meter, begitu pun juga dengan kondisi jalan yang baik dari Bandar Udara Stevanus Rumbewas ke Kampung Sarwandori. Sedangkan jalan dari kampung Sarwandori menuju ke pantai Teluk Mioka yang cukup baik karena jalan aspal yang kasar dan lebar jalan hanya 2 meter sehingga kondisi jalan diberi skor 25. Kondisi yang kurang mendukung untuk aksesibilitas ini adalah jumlah angkutan umum yang masih kurang karena 2 angkutan umum yang sering digunakan oleh masyarakat kampung Sarwandori. Sehingga frekuensi kendaraan umum dari pusat kota Serui ke obyek wisata Teluk Mioka tergolong sedang karena 4-7 kali/hari.

\section{Sarana dan Prasarana Penunjang}

Selain sarana dan prasarana penunjang yang ada di sekitar lokasi juga dapat berpengaruh terhadap perkembangan suatu objek wisata. Dari penelitian yang dilakukan Teluk Mioka memiliki sarana penunjang seperti sarana transportasai angkutan umum, pondok dan kemudian adanya WC. Sedangkan prasarana penunjang adalah puskesmas/klinik, jaringan listrik, jembatan dan jalan. Penilaian terhadap kriteria sarana dan prasarana penunjang dalam perkembangan Teluk Mioka sebagai salah satu daerah tujuan wisata dapat dilihat pada tabel 5 . 
Tabel 5. Hasil penilaian kriteria sarana dan prasarana penunjang Teluk Mioka Kriteria sarana dan prasarana penunjang

\begin{tabular}{llccc} 
No. & Unsur & Bobot & Nilai unsur & Nilai kriteria \\
\hline 1. & Sarana & 3 & 20 & 60 \\
2. & Prasarana penujang & 3 & 20 & 60 \\
\multicolumn{2}{l}{ Total nilai kriteria } & & 40 & 120 \\
\hline
\end{tabular}

Sumber: Data primer, 2016

Keterangan: *Hasil kali antara bobot dengan nilai unsur

Berdasarkan tabel 5, sarana dan prasarana penunjang total nilai kriteria120 karena sarana memiliki nilai kriteria 60 dan prasarana penunjang memiliki nilai kriteria 60 . Dalam pengembangan wisata Teluk Mioka, sarana dan prasarana penunjang merupakan salah satu faktor yang perlu diperhatikan.

\section{Pondok}

Tempat duduk atau pondok yang berada di Teluk Mioka ada 22 pondok dengan 2 lokasi yang berbeda yaitu 13 pondok yang dibangun dekat pantai Teluk Mioka 5 pondok yang dibangun oleh lembaga IFAD dan sisa 8 pondok lain dibangun oleh masyarakat kampung Sarwandori dengan menggunakan dana pemberdayaan kampung dan saat penelitian dilakukan 2 pondok mengalami kerusakan. Sedangkan lokasi lainnya 9 pondok yang dibangun berdekatan dengan rumah warga dan berada di tengah kampung, pondok tersebut tidak terawat, atapnya mengalami kerusakan dan jarang digunakan oleh pengunjung.

\section{Jembatan}

Jembatan yang berada di tengahtengah kampung Sarwandori, dibangun oleh pemerintah dengan tujuan sebagai tempat bersandar kapal speed dan perahu nelayan. Jembatan tersebut memiliki panjang \pm 30 meter dan memiliki lebar \pm 2 meter. Saat penelitian jembatan tersebut digunakan oleh pengunjung sebagai tempat menikmati pemandangan, mancing dan berenang di sekitar jembatan.

\section{Toilet}

Sarana yang dibangun di Teluk Mioka salah satunya toilet. Ada 4 toilet yang dibangun oleh pemerintah dan masyarakat kampung Sarwandori. Toilet ini berada dekat dengan pantai dan digunakan bagi pengunjung pria dan wanita.

\section{Kondisi Lingkungan Lokasi Wisata}

Kondisi lingkungan sekitar lokasi wisata yaitu kondisi daerah dalam radius 1 kilometer dari batas luar objek wisata. Unsur-unsur penilaiannya meliputi tata ruang wilayah objek, status pemilikan lahan, kepadatan penduduk, tanggapan atau sikap masyarakat terhadap pengembangan objek wisata alam, tingkat pengangguran, mata pencaharian penduduk, pendidikan masyarakat sekitar dan media yang masuk. Penilaian terhadap kriteria kondisi lingkungan lokasi wisata Teluk Mioka dapat dilihat pada tabel 6 . 
Tabel 6. Hasil penilaian kriteria kondisi lingkungan lokasi wisata Teluk Mioka Kriteria kondisi lingkungan lokasi wisata

\begin{tabular}{llccc} 
No. & \multicolumn{1}{c}{ Unsur } & Bobot & Nilai unsur & Nilai kriteria \\
\hline 1. & Tata ruang wilayah objek & 5 & 25 & 125 \\
2. & Status pemilikan lahan & 5 & 20 & 100 \\
3. & Kepadatan penduduk & 5 & 10 & 50 \\
4. & Sikap masyarakat terhadap ODWTA & 5 & 25 & 125 \\
5. & Tingkat pengangguran & 5 & 20 & 100 \\
6. & Mata pencaharian penduduk & 5 & 20 & 100 \\
7. & Pendidikan & 5 & 30 & 150 \\
8. & Media masuk & 5 & 25 & 125 \\
& $\quad$ Total nilai kriteria & & 175 & 875 \\
\hline
\end{tabular}

Sumber: Data primer, 2016

Tabel 6 menunjukkan total dari nilai kriteria kondisi lingkungan kawasan wisata yaitu 875 dari unsur yang dinilai yaitu penataan ruang wilayah objek, status pemilikan lahan, kepadatan penduduk, sikap masyarakat terhadap ODWTA, tingkat pengangguran, mata pencaharian penduduk, pendidikan dan media masuk.

Penataan ruang wilayah objek wisata Teluk Mioka diberi skor 25 karena di objek wisata alam Teluk Mioka telah ada penataan ruang yaitu telah dibangun beberapa sarana dan prasarana. Selain itu Teluk Mioka juga memiliki master plan yang dibuat dari BAPPEDA sebagai lokasi wisata yang akan dikembangkan oleh pemerintah kabupaten Kepulauan Yapen. Dalam master plan tersebut ada penataan yang akan dilakukan untuk kampung Sarwandori khususnya Teluk Mioka tetapi tidak sesuai dengan kondisi lingkungan objek wisata. Status pemilikan lahan diberi skor 20 karena tanah milik tanah adat kampung Sarwandori.

Kepadatan penduduk kampung Sarwandori mencapai kampung 331-500 jumlah jiwa. Pada tahun 2015 pemekaran kampung Sarwandori dibagi menjadi 2 kampung yaitu Kampung Sarwandori I dan kampung Sarwandori II. Masyarakat sekitar memiliki mata pencarian sebagian besar sebagai petani dan nelayan. Selain itu, sikap masyarakat kampung Sarwandori terhadap objek mendukung sebagai tempat wisata dan ada pengembangan lebih lanjut sehingga masyarakat akan menerima manfaat ekonomi yang berdampak pada meningkatkan taraf hidupnya.

\section{Penilai Potensi Objek dan Daya Tarik Wisata Teluk Mioka}

Kriteria yang dinilai dari Teluk Mioka adalah daya tarik lokasi wisata tersebut, aksesibilitas untuk bisa mencapai lokasi wisata, sarana dan prasarana penunjang yang ada di sekitar lokasi wisata dan kondisi lingkungan lokasi wisata yang mendukung perkembangan lokasi wisata. Penilaian kriteria objek dan daya tarik wisata Teluk Mioka dapat dilihat pada tabel 7. 
Tabel 7. Hasil penilaian objek dan daya tarik wisata Teluk Mioka

\begin{tabular}{llccc} 
No. & Kriteria & Bobot & Nilai & Skor \\
\hline 1. & Daya Tarik & 6 & 165 & 990 \\
2. & Aksesbilitas & 5 & 125 & 625 \\
3. & Sarana dan Prasarana & 3 & 40 & 120 \\
4. & Kondisi Lingkungan Lokasi Wisata & 5 & 175 & 875 \\
& $\quad$ Tingkat kategori = Baik & & & 2610 \\
\hline
\end{tabular}

Sumber: Data primer, 2016

Berdasarkan tabel 7 di atas, nilai kriteria Teluk Mioka adalah 2610 dan dikategorikan baik. Sehingga lokasi wisata Teluk Mioka memiliki potensi untuk dikembangkan dan berpeluang untuk dijadikan sebagai salah satu daerah tujuan wisata karena memberi penawaran yang baik dari kriteria yang telah dinilai yaitu daya tarik dengan nilai 990, aksesibilitas dengan nilai 625 , sarana dan prasarana penunjang dengan nilai 120 dan juga kondisi lingkungan objek wisata dengan nilai 875 .

\section{Alternatif Pengelolaan Objek Wisata Teluk Mioka}

Berdasarkan hasil penilaian potensi objek dan daya tarik yang dimiliki Teluk Mioka adalah baik, maka alternatif yang dapat diusulkan untuk pengelolaan Teluk Mioka sebagai daerah tujuan wisata alam.

1. Alternatif pengelolaan terhadap daya tarik. Perlu pelestarian potensi wisata alam yang ada, perlu menjaga kebersihan air dan lokasi dari sampah disekitar Teluk Mioka, jaminan keamanan di sekitarnya, budidaya rumput laut sebagai media penelitian dan pendidikan, perlu ditingkatkan pengelolaan rumput laut sebagai bahan makanan selain mie, stick dan agar-agar sehingga menjadi produk kuliner khas Mioka, membuat festival budaya, perlu menambah variasi kegiatan atau atraksi kegiatan untuk menambah daya tarik objek itu sendiri serta merencanakan pengembangan potensi wisata secara alami dan berkelanjutan.

2. Alternatif pengelolaan terhadap aksesbilitas dan sarana prasarana penunjang. Perbaikan jalan menuju Teluk Mioka, penambahan, membuat tempat sampah disekitar lokasi, siapkan tempat untuk membuat parkiran kendaraan roda 2 dan roda 4 yang digunakan oleh pengunjung, membuat penginapan di sekitar teluk, membuat warung makan atau rumah makan, perlu menambah peralatan renang dan perahu atau boot serta memperbaiki sarana dan prasarana yang rusak.

3. Alternatif pengelolaan terhadap kondisi lingkungan lokasi wisata. Perlu melibatkan pihak lain yang prihatin terhadap persoalan konservasi, mengakomodir partisipasi stakeholder lokal, pemberdayaan masyarakat lokal dalam program pengembangan wisata seperti mengadakan pembinaan dan sosialisasi kepada masyarakat, perlu ditingkatkan promosi, menggandeng pelaku pariwisata di dalam dan luar negeri secara berkala bagi pengelolaan Teluk Mioka, perlu adanya usulan sistem zonasi.

\section{DAFTAR PUSTAKA}

Departemen Kehutanan 2007. Kumpulan peraturan dan pedoman pariwisata alam. Pelatihan Pariwisata Alam 31 Oktober -2 November 2007. Direktorat 
Wisata Alam dan Pemanfaatan Jasa Lingkungan. Jakarta: Direktorat Jendral Perlindungan Hutan dan Konsevasi Alam.

Inskeep E. 1991. Tourism planning an integrated and sustainable development approach, van Nostrand Reinhold, New York.

Kementerain Pariwisata Republik Indonesia. 2009. Undang-Undang Repulik Indonesia. Nomor 10 TAHUN 2009. Tentang Keparawisataan.

Mackinnon J, Mackinnon K, Child G and Thorsel J. 1990. Pengelolaan kawasan yang dilindungi di daerah tropika. Yogyakarta: Gadjah Mada University Press.
Oktadiyani P. 2006. Alternatif strategi pengelolaan taman wisata alam Kawah Kamojang Kabupaten Bandung Propinsi Jawa Barat. [skripsi]. Departemen Konsevasi Sumberdaya Hutan dan Ekowisata. Bogor, Fakultas Kehutanan. Institut Pertanian Bogor.

Soemarno 2010. Metode analisis potensi wilayah wisata alam (bahan kajian). Malang.

Wanma AO, Cabuy RL, Peday HFZ, Beljai M dan Morimuzendi, AS. 2013. Ethnobotanical aspect of noken: Case study in the high mountain indigenous community of Papau Island, Indonesia. Indian Journal of Traditional Knowledge, 12(2): 202-208. 